\title{
Evangelizar la historia: la reapertura de los procesos de beatificación de los mártires de la Guerra Civil
}

Evangelizing History: the Reopening of the Beatification Processes of the Spanish Civil War Martyrs

Vicente Jesús Díaz Burillo Universidad Autónoma de Madrid

DOI: http://dx.doi.org/10.15366/bp2018.19.010 Bajo Palabra. II Época. No19. Pgs: 211-228 


\section{Resumen}

La Iglesia católica suministró soporte moral e ideológico al régimen franquista prácticamente desde el primer momento. Uno de los elementos con los que la institución eclesial contó para lograr lo anterior fueron los procesos de beatificación y canonización de los "mártires de la cruzada". El devenir de estos procesos da cuenta del devenir de la propia institución eclesial durante el siglo XX en España: de aquella reivindicación de los "mártires de la cruzada", en la primera posguerra, a la reivindicación de sus "mártires de la fe" ya en democracia, la Iglesia ha adaptado su relato sobre la Guerra Civil a las condiciones de cada momento histórico.

Palabras clave: mártires de la cruza$d a$, mártires por la fe, procesos de beatificación, Transición española, memoria histórica.

\section{Abstract}

The Catholic Church provided moral and ideological support to the Franco regime from the outset. One of the elements with which the ecclesial institution counted to achieve this were the processes of beatification and canonization of the "martyrs of the Crusade". The development of these processes accounts for the development of the ecclesial institution itself during the 20th century in Spain: from the vindication of the "martyrs of the crusade", in the first postwar period, to the claim of their "martyrs of faith" already in democracy, the Church has adapted its account of the Civil War to the conditions of each historical moment.

Keywords:martyrs of the crusade, martyrs of faith, processes of beatification, Spanish transition, historical memory. 
Como sabes mejor que yo, Señor Ministro, tanto por tu formación de jurista como por ser buen conocedor de la vida pública, el lenguaje de los poderes políticos está en función de la especifica naturaleza de cada uno de ellos. Y el lenguaje de la Iglesia romana, por la peculiarísima entidad de su potencia espiritual y pública, está "tout fait de symboles", como dirían los galos. En el protocolo y en el ritual pone la Santa Sede un cuidado exquisito, porque son los simbolos externos de su poder, a falta de bombas y cañones. Si esto es así, entonces la cuestión de los cinco "beatificanda" no conviene tratarlos como asunto baladi, sino como problema de Estado ${ }^{1}$.

G onzalo Puente Ojea, embajador de España ante la Santa Sede entre 1985 y 1987, parecía tenerlo claro: la reapertura de los procesos de beatificación de los considerados por la Iglesia mártires de la Guerra Civil debía ser considerada como un problema de Estado. La reflexión la hacía Puente Ojea con ocasión de la primera de las ceremonias que se celebró en el Vaticano con motivo de la reapertura de aquellos procesos de beatificación. Fue el 29 de marzo de 1987, y con ella se inauguraba una forma de escenificación, de "espectacularización" religiosa, que se repetiría con asiduidad en los ańos siguientes. Hasta tal punto fue así que, ya en pleno siglo XXI, España era considerada por la jerarquía eclesiástica "una tierra bendecida por la sangre de los mártires". Así se expresaba Ángel Amato, Prefecto de la Congregación para la causa de los Santos, en 2013. El contexto venía dado por la ceremonia de "macrobeatificación" celebrada en el Vaticano en octubre de aquel año, ceremonia en la que se exaltó la figura de 522 mártires que "en España, en el siglo XX, derramaron su sangre para dar testimonio de Jesús" ${ }^{2}$. En esta ocasión a la ceremonia en Roma asistieron varios representantes públicos españoles: Artur Mas, presidente de la Generalitat de Catalunya; Alberto Ruiz Gallardón, ministro de justicia; Jorge Fernández Díaz, ministro del interior; e incluso un inspector general del ejército, Ricardo Álvarez-Espejo. La escenifi-

\footnotetext{
1 "Carta del Embajador de Espańa ante la Santa Sede, Gonzalo Puente Ojea, al Ministro de Exteriores, Francisco Fernández Ordoñez”, 12 de diciembre de 1986, en Puente Ojea, G., Mi embajada ante la Santa Sede. Textos y Documentos, 1985-1987. Madrid, FOCA, 2002, p. 298.

2 Religión digital, 13 de octubre de 2013. Disponible en internet: http://www.periodistadigital.com/religion/espana/2013/10/13/martires-iglesia-religion-papa-amato-cardenal-tarragona-espana-francisco-dios.shtml
} 
cación en aquel 2013 se había vuelto ya cotidiana: ceremonias de beatificación grandilocuentes y multitudinarias, una gran cobertura mediática, y la asistencia de representantes públicos españoles.

Pero no siempre fue así. Los procesos de beatificación de los mártires de la Guerra Civil habían sido paralizados durante el papado de Pablo VI. En aquel momento se consideró imprudente seguir adelante con los mismos en tanto podrían malinterpretarse políticamente y hacer que la Iglesia siguiera apareciendo de una forma demasiado clara vinculada al franquismo. Sin embargo, en los años ochenta, ya consolidada la democracia y con Juan Pablo II en el papado...

Desde aquel mes de marzo de 1987, España ha sido uno de los países donde la reforma de los procesos de canonización y su escenificación en grandes ceremonias públicas se ha dado con más asiduidad. Se han realizado más de 1500 canonizaciones y beatificaciones de mártires de la Iglesia, y un número desconocido de ellas se encuentra en proceso de tramitación ${ }^{3}$. Y es que la Iglesia se ha convertido en un auténtico agente de memoria. En este sentido, podríamos decir que la Iglesia construye "cuadros sociales de memoria" que, con un relato destinado en un primer momento a sus fieles, excede los márgenes del consumo interno y posiciona a la institución católica en el debate público sobre la memoria ${ }^{4}$. La "revancha" religiosa que la Iglesia católica protagonizó en las últimas décadas del siglo XX no sólo se hizo pretendiendo "evangelizar" el espacio público y político con su doctrina; también se pretendió ocupar el pasado, evangelizar la historia.

Para comprender en su justa medida el proyecto memorialístico católico es necesario relacionarlo con un proceso que excede los límites nacionales. Porque es verdad que la reivindicación de sus mártires tiene en el marco nacional español una escenificación privilegiada, unos matices claramente diferenciadores. Aun así, es imposible entender este paso a una actitud reivindicativa, como de revancha, de la institución eclesial sin atender a su propia dinámica interna. Una dinámica que tiene en 1978, con la llegada al papado de Karol Wojtyla, su punto de inflexión, coincidiendo en España, por tanto, con la aprobación de la Constitución y el comienzo del proceso de consolidación democrática. Durante este periodo se fue construyendo un relato que insertaba el proceso transicional de una manera determinada en el conjunto de la historia de España y en el que la dialéctica memoria-olvido tuvo un gran protagonismo. En relación a esa dialéctica cabe entender la reapertura de los procesos de beatificación y la relectura de la historia

\footnotetext{
${ }^{3}$ Existe una base de datos digital con información sobre los procesos de beatificación y canonización de "Los Santos y Beatos mártires de la persecución religiosa del siglo XX en Espańa”. En: http://www.beatificacion2013. com/index.php/base-de-datos-de-martires.

${ }^{4}$ Halbwachs, M, Les cadres sociaux de la mémorie. Paris, Albin Michel, 1995 (1925).
} 
de la Iglesia católica durante el siglo XX que el relato construido alrededor de la figura del mártir pretendía.

\section{Memoria y olvido en la Transición política española.}

Escribía Gregorio Morán que "la primera igualdad que instauró la democracia en España fue la de que todos somos iguales ante el pasado. Una garantía para mantener la desigualdad ante el futuro. Nos convertimos en un reino de desmemoriados". Morán ponía el acento, así, en un aspecto que fue fundamental en la Transición española y que define una de las dialécticas que atraviesan los relatos de los distintos agentes involucrados en la Transición: la dialéctica memoria-olvido. La pregunta es fundamental: cómo construir un régimen democrático en un país que pretende dejar atrás cuarenta años de dictadura, ¡es necesario construirlo haciendo memoria, señalando a los responsables del anterior régimen, juzgándolos? ¿O más bien el nuevo régimen democrático debe partir del olvido, obviando los crímenes del pasado y renunciando a exigir responsabilidades? ${ }^{6}$

Parece claro que el modelo seguido en aquellos años, y que definió el modelo transicional español, fue el del olvido. Sólo así, se argumentaba, podría garantizarse que el proceso de transición a la democracia tuviera éxito. "Que los muertos entierren a los muertos", escribía Javier Pradera en el El País, uno de los periódicos con mayor tirada en los años que sucedieron a la Transición y el que en buena medida mejor representó el "sentido común" que sobre la memoria se haría hegemónico en España 7 .

Cuenta Paloma Aguilar que las políticas de la memoria por parte del Estado en aquellos años fueron prácticamente inexistentes. No hubo iniciativas de carácter público destinadas a difundir o consolidar una determinada visión de un pasado que se consideraba traumático ${ }^{8}$. Podríamos decir, en este sentido, que el Estado delegó de su función de "agente de memoria". Sin embargo, y como señala Javier Rodrigo, que desde el Estado se renunciara a retomar de alguna forma el recuerdo de la Guerra Civil no significa que en aquellos ańos no hubiera memoria de la guerra. Sobre la misma se habló y se publicó. La Iglesia, como veremos,

\footnotetext{
5 Morán, G., El precio de la transición. Madrid, Akal, 2015, p. 107.

${ }^{6}$ Kritz N. J. (ed.), Transitional Justice: How Emerging Democracies Reckon with Former Regimes. Washington, United States Institute of Peace Press, 3 vols., 1995; Teitel, R. G., Transitional Justice, New York, Oxford University Press, 2000.

7 Izquierdo Martín, J., “Que los muertos entierren a los muertos». Narrativa redentora y subjetividad en la Espańa postfranquista”, Pandora, 12, 2014, pp. 43-63.

8 Aguilar Fernández, P., Políticas de la memoria y memorias de la política. Madrid, Alianza Editorial, 2008.
} 
es ejemplo de ello. Pero no hubo, como decía, una política estatal que acabara con el relato impuesto desde las instituciones franquistas. Más bien, y como nos cuenta Javier Rodrigo, lo que hubo fue una "renuncia política que, amparada en la reconciliación nacional, dejaba intactos símbolos, físicos o no, de la guerra y la dictadura, en su afán de no herir sensibilidades ni reabrir heridas" 9 .

En opinión de Manuel Artime, la confección de una narrativa oficial o de reconciliación tuvo mucho que ver con lo anterior ${ }^{10}$. Legitimada por los que él denomina "historiadores liberales" 11 , aquella narrativa sobre el pasado presentaba a la democracia del 78 como la culminación de un largo proceso modernizante. Se fue imponiendo, confeccionada a manos de la "historiografía liberal" ya desde el tardofranquismo, una narrativa que fue la que vertebró la llamada "Cultura de la transición" ${ }^{12}$, narrativa que quedó consolidada durante los años ochenta. La reconciliación nacional representaba en este relato que se haría hegemónico el desenlace de aquella apuesta por el progreso y por la modernidad que la Transición, por fin, había cumplido, homologando las instituciones españolas a las del resto de países europeos. Se implementaba así una narrativa lineal y aproblemática en la que la reconciliación nacional, y su traducción política a través del "consenso", se convertía en la piedra de toque de la democracia naciente. En este relato, la Constitución de 1978 se entendía como momento fundante de una cultura democrática en Espańa; una cultura democrática que no sabía, o no quería, encontrar en el pasado referencias que le sirvieran de fundamento. En este contexto, las referencias a la II República no podían ser sino consideradas peligrosas, alentadoras de discursos que, como en el pasado, solo podían llevar a los españoles a la confrontación. No cabía más que "echar al olvido" aquellos proyectos emancipatorios que en el pasado habían nutrido las aspiraciones de republicanos, anarquistas, socialistas o comunistas.

Con la Transición a la democracia, por tanto, se ponía fin a una larga etapa plagada de errores que habían lastrado nuestra incorporación definitiva al mundo moderno. Una de las primeras tareas encomendadas a la nueva democracia sería la de suturar las heridas que había dejado en los españoles un enfrentamiento que se remontaba no ya a 1936, sino, al menos, a $1812^{13}$. La Transición, según este rela-

\footnotetext{
9 Rodrigo, J., Hasta la raiz. Violencia durante la guerra civil y la dictadura franquista. Madrid, Alianza Editorial, 2008, p. 210.

${ }^{10}$ Artime, M., España. En busca de un relato. Madrid, Dykinson, 2016.

11 "La Historiografía Liberal sería aquella, que, en el ámbito académico de la Historia, defienda la que ha sido la tesis popular de la 'tercera España'; esto es, el emplazamiento a dejar atrás toda clase de querellas nacionales y polémicas histórico-políticas, lo que va a significar no sólo alejar la política de la mirada histórica, sino también la historia de la mirada política”, ibid., p. 26.

12 Guillem Martinez, G. (coord.), CT o la cultura de la transición: Crítica a 35 años de cultura española. Madrid, Debolsillo, 2012.

13 Juliá, S., Historia de las dos Españas, Madrid, Taurus, 2004.
} 
to, vendría a suponer un punto de discontinuidad en la deriva política española, el acontecimiento que dividía en dos mitades cualquier relato que se pretendiera construir sobre la historia reciente de España ${ }^{14}$.

\section{La Iglesia católica contra el olvidoः de "mártires de la cruzada" a "mártires por la fe".}

La Iglesia ESPAÑola COlaboró En la CONSTRUCCión y consolidación de aquel relato que se hizo hegemónico durante la Transición. Hasta tal punto fue así, que el año 1975 fue nombrado oficialmente por la institución católica Año de la Reconciliación ${ }^{15}$. La jerarquía eclesiástica pretendía desligarse así de aquella Iglesia que, desde el primer momento, había legitimado el régimen franquista surgido del golpe de Estado militar de julio de $1936{ }^{16}$. De aquella cobertura moral, que encuentra en la publicación de la Carta Colectiva del episcopado en la que a la guerra se le otorgaba el carácter de cruzada su mejor representación ${ }^{17}$, hasta el final de la dictadura, la Iglesia participó, cuando no fue uno de sus diseñadores, en la reproducción de los relatos históricos que en cada momento se hacían oficiales.

La anterior dinámica se alteró a partir de 1978. Con la llegada de Karol Wojtyla al papado, la Iglesia católica emprendió una carrera por convertir de nuevo al catolicismo en un agente político de primer orden ${ }^{18}$. En ese nuevo proyecto católico que se imponía desde Roma, también la historia se convirtió en un espacio a evangelizar. Este empeño tuvo en España unas características singulares. No podía ser de otro modo, habiendo formado parte la Iglesia católica de una forma tan intensa de los principales acontecimientos que habían atravesado la historia de España en el siglo XX. En la figura del mártir, en el relato construido a su alrededor, puede observarse perfectamente la deriva eclesial durante gran parte del siglo XX. Desde el primer franquismo y hasta los años ochenta, ya en democracia, aquellos mártires sufrieron una transformación: de "mártires de la Guerra Civil" o "mártires de la Cruzada" a "mártires de la persecución religiosa" o "mártires por la fe".

\footnotetext{
${ }_{14}$ Artime, M., España. En busca de un relato, op. cit., p. 252.

15 Aguilar Fernández, P., Políticas de la memoria y memorias de la política, op. cit. p. 245.

16 Casanova, J., La Iglesia de Franco, Barcelona, Crítica, 2005.

${ }_{17}$ Carta colectiva de los obispos españoles a los obispos de todo el mundo con motivo de la guerra en España, Pamplona, Gráficas Descansa, 1937. Cit. en Iribarren, J. (ed.), Documentos colectivos del episcopado español 1870-1974, Madrid, Editorial católica, 1974, pp. 219-242.

${ }^{18}$ Díaz Burillo, V. J., "Integralismo católico posconciliar: un análisis del imaginario político de la Iglesia en democracia”, en Romerales, E. y Zazo, E. (eds.), Religiones en el espacio público, Barcelona, Gedisa, 2016, pp. 137-156.
} 
¿Cuál ha sido el recorrido que ha seguido ese proceso desde aquel primer momento en que la categoría de "mártir" se hacía extensiva a los caídos del bando franquista de la contienda espańola, hasta su reapertura, ya en los años ochenta, momento en que aquellos mártires se convierten en "mártires de la persecución religiosa"? Fue en 1938 cuando, instalado en Burgos el mando del bando franquista, y firmado por Francisco Franco, se publicó un Decreto en el que se pedía conmemorar la muerte de José Antonio Primo de Rivera. En su articulado se exponía la forma en que esto debía hacerse, desde la creación de cátedras para estudiar y dar a conocer su pensamiento, hasta la instrucción de que el nombre de José Antonio se incorporara al de las calles de todos los pueblos de España. Además, en su artículo segundo podía leerse: "Previo acuerdo con las autoridades eclesiásticas, en los muros de cada Parroquia figurará una inscripción que contenga los nombres de sus Caídos, ya en la presente Cruzada, ya víctimas de la revolución marxista" ${ }^{19}$. El Decreto se hizo efectivo, e incluso hoy en día pueden verse en las fachadas de innumerables parroquias grabados en piedra los nombres de aquellos "caídos" en la "Cruzada", con el nombre de José Antonio en lugar preeminente. $\mathrm{Y}$ es que la connivencia del régimen que surgió de aquella Guerra Civil con la Iglesia fue tal desde prácticamente el primer momento.

La referencia a los mártires de la cruzada se convirtió de este modo en uno de los elementos simbólicos utilizados para legitimar el régimen franquista. Pero al tiempo que suministraba aquella legitimidad al Estado otorgando el carácter de mártir a sus caídos, la Iglesia construía sus propias referencias simbólicas a partir de la figura de aquellos religiosos que habían muerto, ya en el frente, ya en la retaguardia, durante la Guerra Civil. Estos constituían la prueba del carácter "persecutorio" que la República había tenido frente a la religión católica. Es esta una acusación, la del carácter abiertamente "antieclesial y aun anticristiano" del régimen republicano, que está entre las primeras que la Iglesia esgrimió como excusa para dar su apoyo al régimen surgido de la sublevación militar del 36:

Dejando otras causas de menor eficiencia, fueron los legisladores de 1931, y luego el poder ejecutivo del Estado con sus prácticas de gobierno, los que se empeñaron en torcer bruscamente la ruta de nuestra historia en un sentido totalmente contrario a la naturaleza y exigencias del espíritu nacional, y especialmente opuesto al sentido religioso predominante en el país. La Constitución y las leyes laicas que desarrollaron su espíritu fueron un ataque violento y continuado a la conciencia nacional. Anulando los derechos de Dios y vejada la Iglesia, quedaba nuestra sociedad enervada, en el orden legal, en lo que tiene de más sustantivo la vida social, que es la religión ${ }^{20}$.

\footnotetext{
19 Boletin Oficial del Estado, 140, 17 de noviembre de 1938, p. 2432.

${ }_{20}$ Carta colectiva de los obispos españoles a los obispos de todo el mundo con motivo de la guerra en España, op. cit. p. 225.
} 
Acusación que, aun siendo del primer momento, no ha dejado de esgrimirse hasta tiempos ya de democracia consolidada. Así se expresaba el cardenal Tarancón en sus Confesiones:

El advenimiento de la República en abril de 1931, que sorprendió a los mismos republicanos y que políticamente no tenía, al parecer, explicación, fue la consecuencia de muchos factores -económicos y sociales preferentemente- y tomó desde el comienzo un carácter antieclesial y aun anticristiano [...] el nuevo régimen tuvo ya desde el primer día un carácter abiertamente anticatólico que se convirtió muy pronto en persecutorio ${ }^{21}$.

El relato, ya en los años ochenta, con la democracia surgida de la Transición en proceso de consolidación, repetía los tópicos del argumentario que desde el momento que la Iglesia dio su apoyo al levantamiento fue asumido por la mayoría de la jerarquía católica espańola. Esta actualización del relato católico anti-republicano tiene, sin embargo, algunas especificidades. Porque el cardenal Tarancón no reproducía exactamente todos los elementos que sí informaban el núcleo del nacionalcatolicismo y que engarzaban lo español con la religión católica de tal forma que atacar a esta significaba atacar a la misma "conciencia nacional". La identificación entre catolicismo y nación quedaba en este caso difuminada ${ }^{22}$. Esto, sin embargo, no le impedía justificar la actitud de los obispos de aquel momento:

Los obispos españoles estaban seriamente comprometidos. Comprometidos, sobre todo, ante la gran masa de católicos que habían dado, con hechos a veces heroicos más que con palabras, el carácter de "cruzada" a la Guerra que nos tenía divididos; comprometidos ante la Santa Sede y el episcopado mundial, a quienes debían explicar la realidad española que ellos no acertaban a comprender; y comprometidos también con las autoridades de la España nacional que tenían el pleno convencimiento de que estaban defendiendo a la Iglesia.

Yo me atrevería a afirmar que los obispos no tuvieron más remedio que manifestarse colectivamente de la manera que lo hicieron. ${ }^{23}$

Más allá del blanqueamiento que de la actitud de aquellos obispos colaboracionistas con la sublevación hacía el "cardenal del cambio" ${ }^{24}$, lo que en este punto es

\footnotetext{
${ }^{21}$ Enrique y Tarancón, V., Confesiones, Madrid, PPC, 1996, pp. 204-205.

22 "El catolicismo y, por tanto, la Iglesia, se consideraban casi como patrimonio nacional. 'España no puede dejar de ser católica sin dejar de ser España', repetíamos todos con frecuencia hasta hace algunos años”, Ibid., p. 203.

${ }^{23}$ Ibid., p. 206.

24 "Cardenal del cambio", feliz slogan que el sacerdote y periodista José Luis Martín Descalzo puso con éxito en circulación, y que, podríamos decir, se ha convertido en un mito más de la Transición. Martín Descalzo, J. L., Tarancón, el cardenal del cambio, Madrid, Planeta, 1982; Laboa, J. M., "El cardenal Tarancón, testigo del cambio", Cuenta y razón, 12, 1983, pp. 95-104; Infiesta, J., "Tarancón, el otro motor del cambio", Cuenta y razón, 96, 1996, pp. 64-67.
} 
importante subrayar es la línea de continuidad del relato construido por la Iglesia en aquellos primeros momentos de la guerra y la adecuación de aquel discurso a las necesidades que el momento social y político exigía en los ańos ochenta. No existen en este caso referencias contundentes a los caídos, la consustancialidad de lo religioso y lo nacional ha desaparecido... y, sin embargo, Tarancón no renunciaba a reivindicar y justificar la actitud de la jerarquía católica en relación a la República y a la sublevación militar. Lo anterior es más llamativo si tenemos en cuenta que unos años antes de que el cardenal Tarancón escribiera sus memorias, él mismo había sido protagonista de lo que había sido un intento más o menos exitoso de asumir responsabilidades en aquel golpe de Estado contra la República y la posterior Guerra Civil ${ }^{25}$.

¿Qué ha pasado en los años que van de aquella tímida asunción de culpas en los primeros ańos de la década de los setenta, a los años en los que, junto a la reivindicación de sus mártires, se retomaba el tópico de la persecución religiosa para justificar a aquellos obispos que "no tuvieron más remedio que manifestarse colectivamente de la forma en que lo hicieron"? Durante los años sesenta Pablo VI había considerado la necesidad de paralizar los procesos de beatificación y canonización que desde los años cuarenta se habían abierto para ensalzar la figura de los mártires de la guerra de España. En aquel momento se pretendía aunar en un solo proceso la beatificación de todos los mártires, lo que, en opinión de la jerarquía vaticana, podría dar al proceso la apariencia de juicio político. En 1975, tras la muerte de Franco y a instancias de Pablo VI, aquellos procesos fueron finalmente paralizados ${ }^{26}$. Se quería evitar a toda costa que, llegado a su fin el régimen franquista, la Iglesia apareciera demasiado vinculada al bando de los sublevados durante la Guerra Civil.

La Iglesia contribuía de esta forma al "pacto de silencio" que primó entre la mayoría de los agentes que fueron protagonistas en el proceso de Transición. El progreso y la reconciliación eran incompatibles en aquel momento con reivindicaciones sobre el pasado, y de los discursos oficiales desaparecieron las referencias a la Guerra Civil. La segunda Ley de Amnistía de 1977 acabaría por institucionalizar el silencio como paradigma oficial al que habría que atenerse so pena de querer reabrir heridas del pasado o, incluso, poner en peligro el proceso democratizador en Espańa. Y la Iglesia católica cumplió con este programa.

\footnotetext{
25 "Reconocemos humildemente y pedimos perdón porque nosotros no supimos ser, a su tiempo, verdaderos ministros de reconciliación en el seno de nuestro pueblo, dividido por una guerra entre hermanos”, podía leerse en las propuestas presentadas para su debate en la famosa Asamblea Conjunta de obispos y sacerdotes celebrada en septiembre de 1971. La propuesta, sin embargo, no consiguió la mayoría necesaria para su aprobación. Secretariado Nacional del Clero (ed.): Asamblea Conjunta Obispos-Sacerdotes, Madrid, BAC, 1971, p. 170.

${ }^{26} A B C, 18$ de octubre de 1983 , p. 48.
} 
En los años ochenta, sin embargo, los procesos de beatificación fueron reabiertos. En 1982 el cardenal Pietro Palazini, Prefecto de la Congregación para la Causa de los Santos, informó a Juan Pablo II de la existencia de multitud de procesos paralizados. Poco tiempo después, en octubre de 1983, durante la celebración de un Sínodo de Obispos en el Vaticano, se comunicó oficialmente la reapertura de los procesos de beatificación de los mártires de la guerra en España ${ }^{27}$. Quedaba atrás la prudencia que había guiado hasta aquel momento a la oficialidad eclesiástica vaticana. Los procesos se reabrieron y pudieron, además, beneficiarse de la reforma del Código de Derecho Canónico llevada a cabo en los primeros años del pontificado de Karol Wojtyla. Esta reforma, realizada en 1983, flexibilizó los procesos reduciendo de 50 a 5 años los necesarios para iniciar el proceso beatificación o canonización a partir de la muerte del candidato. Además, los procesos no tendrían que pasar ahora un doble trámite para su aprobación, en la diócesis a la que perteneciera el mártir y en el Vaticano, sino que el proceso se simplificaba dependiendo a partir de esta reforma la apertura y cierre del proceso únicamente de la diócesis de origen.

Daba comienzo así la reapertura de unos procesos de beatificación de los que en esta ocasión serían llamados "mártires por la fe", poniéndose en marcha de esta forma una deriva que llevó a la Iglesia española a construir un relato memorialístico que con los años se fue haciendo más contundente. En aquella ocasión, a finales de 1983, las protagonistas fueron tres carmelitas descalzas de Guadalajara cuyos procesos de beatificación se habían iniciado en febrero de 1946. Se reabrían sus procesos, pero no sin el temor a que esto conllevara la reapertura de "una grave herida en la carne de nuestra historia reciente". Así lo escribían en las páginas del $A B C$ :

La posible próxima beatificación de tres religiosas carmelitas, brutalmente asesinadas en Guadalajara el 24 de julio de 1936, así como la reapertura de algunas otras, referentes a obispos y sacerdotes muertos en nuestra guerra civil, plantean en la España de hoy un nada fácil problema. Por un lado, el honor debido a posibles auténticos mártires que dieron su vida claramente por Cristo (y que no deben ser discriminados por el hecho de que su muerte se viera envuelta en un conflicto civil) y, por otro, la reapertura de una grave herida en la carne de nuestra historia reciente ${ }^{28}$.

En otras palabras: incluso desde los medios de comunicación cercanos a la Iglesia católica se temía que con la reapertura de los procesos de beatificación se transgrediera aquel "pacto de silencio" que habían mantenido la mayor parte de las instituciones que habían sido protagonistas en la Transición. La Iglesia de Wojtyla,

\footnotetext{
27 La Vanguardia, 18 de octubre de 1983, p. 22; $A B C, 18$ de octubre de 1983, pp. 48-49.

${ }^{28} A B C, 18$ de octubre de 1983 , p. 48.
} 
sin embargo, no renunció al uso propagandístico que le ofrecía el relato sobre el martirologio en España. Al contrario, desde aquel año de 1983, la Iglesia española asumió el programa memorialístico que con la reapertura de los procesos de beatificación se iniciaba en Roma. Desde ese momento, la figura del mártir volvió a cobrar protagonismo en Espańa. Para su reivindicación se puso en funcionamiento todo el entramado mediático del que disponía la Iglesia: las multitudinarias ceremonias de beatificación se convirtieron en una oportunidad más para relanzar a la institución eclesial a la conquista del espacio público y político.

\section{La pastoral de la memoria: evangelizar la historia.}

LA REAPERTURA DE LOS PROCESOS BEATIFICACIÓN, así como la escenificación de las ceremonias posteriores (esa espectacularización que se hizo norma durante el papado de Juan Pablo II) muestra, primero, la transgresión por parte de la Iglesia católica de aquel "pacto de silencio" que había vertebrado los relatos sobre la Guerra Civil durante la Transición política espańola; y, segundo, nos muestra a una Iglesia dispuesta a recuperar la iniciativa ya no sólo en el empeño por construir una memoria que salvara o blanqueara su papel durante la Guerra Civil, sino por proponer, a través de la figura del mártir, un modelo convivencial exportable más allá de los límites de lo religioso.

Aquella ceremonia de marzo de 1987 en el Vaticano fue la primera de muchas que contribuyeron a asentar la "pastoral de la memoria" que la Iglesia católica propuso en adelante. Una construcción memorialística que pretendía situar al catolicismo al margen de la contienda política e ideológica, aquella que identificó a los dos bandos durante la Guerra Civil. En el año 2000, y como respuesta a la controversia planteada por la beatificación de casi 500 mártires declarados hasta aquel momento, Juan José Ajenjo, portavoz de la Conferencia Episcopal, señaló que, en la Guerra Civil, la Iglesia había sido "sujeto paciente y víctima" 29.

Es esta una de las características principales de este nuevo relato: la reconfiguración de la imagen del mártir permitía a la Iglesia católica situarse al margen de las disputas ideológicas que definían a los bandos enfrentados en la Guerra Civil. De la misma forma, y al tiempo que apartaba a sus mártires de su posición en el relato franquista, la Iglesia proponía a estos como ejemplo de una supuesta "tercera España" que podría servir como imagen de la reconciliación entre los españoles.

\footnotetext{
29 "Los Obispos insisten en que la Iglesia fue 'sujeto paciente y víctima' de la Guerra Civil”, El País, 13 de abril de 2000 .
} 
Los mártires, "sujetos pacientes y víctimas" de aquel conflicto, venían a representar ahora a aquellos españoles que, ajenos a los excesos ideológicos de los años treinta, habían sido víctimas de los mismos; el mártir se proponía, en definitiva, como ejemplo de la capacidad para superar, sin odios, la secular tendencia de los espańoles a enfrentarse entre ellos ${ }^{30}$.

Para que esta propuesta memorialística funcionara verdaderamente como una propuesta superadora de aquella supuesta tendencia cainita que afectaba a los españoles, era necesario establecer algunas puntualizaciones históricas. Una de ellas fue la introducción de una discriminación axiológica entre los muertos de la Guerra Civil:

Durante las guerras hay caídos en acciones bélicas [...] en las retaguardias hay víctimas de la represión política [...] Pero a los que mueren a causa de la persecución religiosa en el contexto de una guerra o fuera de ella, hay que llamarles mártires de la fe. Esta es una diferencia sustancial, porque el mártir no interviene en la guerra; al mártir no se le mata por razones políticas, sino por motivos religiosos" 31 .

La propuesta es, conociendo cual fue el papel de la Iglesia en aquellos años, cuando menos, atrevida. Pero, señala el sacerdote-historiador, "es necesario acabar con un obstinado silencio", el silencio "de la historiografía marxista, y, en general, de izquierdas, sobre lo que realmente fue la persecución religiosa española”, porque, añade, este silencio "recuerda las reticencias de los historiadores de hace cincuenta años sobre el nazifascismo" 32 .

La historia necesita de evangelistas, parece clamar el apologeta, la historia requiere de la evangelización. Y los mártires son uno de los instrumentos que han encontrado desde la institución católica para llevar lo anterior a cabo. En relación a estos, Vicente Cárcel Ortí añade:

Todos ellos murieron durante la mayor persecución que ha conocido la historia de la Iglesia con cerca de diez mil "mártires de la fe", que no deben confundirse con los soldados

\footnotetext{
${ }^{30}$ Berretini, M., "A settant'anni dalla Carta Collettiva dell'Episcopato spagnolo: Jerarquía, martirio, memoria colletiva", en Accial, E. y Quaggio, J. (eds.): Un conflitto che non passa. Storia, memoria e rimozioni della guerra civile spagnola, Pistoria, ISRPT, 2012, pp. 42-64.

${ }^{31}$ Carcel Ortí, V., Caidos, víctimas y mártires. La Iglesia y la hecatombe de 1936, Madrid, Espasa, 2008, p. 403.

32 Carcel Ortí, V., La gran persecución. España, 1931-1939, Barcelona, Planeta, 2000. El recurso a los tópicos de la apologética franquista, por otra parte, no se agota en su anti-republicanismo: "El primer mérito de Franco fue ganar la guerra y salvar a España de la dictadura stalinista. Acabó con el conflicto y la mayor parte de los españoles comenzó a respirar, porque después de más de cien años de revueltas y levantamientos militares se acabaron las guerras civiles. Franco instauró un gobierno personal, cada vez más moderado y tolerante, que promovió la reconciliación nacional, evitó al país los horrores de la segunda guerra mundial y firmó un tratado con Estados Unidos". Ibid. p. 25.
} 
"caídos en los campos de batalla", que fue muy dura durante la guerra, tanto en la zona republicana como en la nacional, y lo fue durante varios ańos más una vez terminado el conflicto por parte del nuevo régimen. Pero todos los muertos no son iguales, aunque los crímenes son igualmente detestables y condenables cualquiera que sea quien los cometa ${ }^{33}$.

La maleabilidad de la figura del mártir permite tal discriminación axiológica. Una discriminación axiológica entre los muertos de la Guerra Civil que no se ha quedado en la expresión de unas propuestas académicas e historiográficas más o menos discutibles, sino que ha tenido una buena acogida en los órganos institucionales católicos. En 2007, y con motivo de la beatificación de 498 mártires en Tarragona, desde la Conferencia Episcopal se emitió un comunicado en el que podía leerse lo siguiente:

Las guerras tienen caídos en uno y en otro bando. Las represiones políticas tienen víctimas, sea de uno o de otro signo. Sólo las persecuciones religiosas tienen mártires, sean de una o de otra ideología, de una o de otra preferencia -o pertenencia- política o incluso de distintas confesiones religiosas ${ }^{34}$.

Pocos años después, en abril de 2013, la Asamblea Plenaria de la Conferencia Episcopal Española aprobaba un documento en el que exponían que: "Celebrando su memoria y acogiéndose a su intercesión, la Iglesia desea ser sembradora de humanidad y reconciliación en una sociedad azotada por la crisis religiosa, moral, social y económica, en la que crecen las tensiones y los enfrentamientos" ${ }^{35}$. Los mártires del siglo XX, así, no sólo servían como ejemplo de un tipo especial de victimización, también servían para ejemplificar un proyecto ideológico integral en oposición a las "ideologías materialistas", como invitación a la "conversión" para así "apartarse de los ídolos de la ambición egoísta" ${ }^{36}$.

Tenemos por tanto que la Iglesia católica adecuó su discurso sobre los mártires a las necesidades que requería cada contexto histórico. Esta adecuación servía tanto para actualizar el relato sobre su papel en la Guerra Civil como para participar en el debate público sobre la memoria histórica. De esta forma, la Iglesia católica no sólo construía un modelo de creyente que debía servir como propuesta para sus

33 Carcel Ortí, V., Caidos, Víctimas y mártires. La Iglesia y la hecatombe de 1936, op. cit. p. 37.

34 Oficina de Información de la Conferencia Episcopal Española: Beatificación de 498 mártires del siglo XX en España, 28 de octubre de 2007.

35 CI Asamblea Plenaria de la Conferencia Episcopal Española: "Los mártires del siglo XX en Espańa, firmes y valientes testigos de la fe. Mensaje con motivo de la Beatificación del Año de la fe, en Tarragona, el 13 de octubre de 2013”, Conferencia Episcopal Espańola, 19 de abril de 2013, p. 3.

36 Ibid. p. 3. 
fieles, sino que entraba de lleno en la disputa por imponer un modelo convivencial con pretensiones de validez para toda la sociedad. De esta forma, el sujeto especial de victimización que representa el mártir pasaba a formar parte del programa de "evangelización" del espacio público y político que, especialmente desde 1978, ordena la acción política de la Iglesia católica. La mirada en este caso se dirigía hacia el pasado, hacia la historia: un maleable espacio a evangelizar siempre que la mirada estuviera, eso sí, convenientemente mediada por la fe. 


\section{REFERENCIAS BibLIOGRÁficas}

Aguilar Fernández, P., La memoria histórica de la guerra civil española (19361939). Un proceso de aprendizaje político, Madrid, Centro de Estudios Avanzados en Ciencias Sociales, 1995.

Aguilar Fernández, P., Políticas de la memoria y memorias de la política. Madrid, Alianza Editorial, 2008.

Artime, M., España. En busca de un relato. Madrid, Dykinson, 2016.

Berretini, M., "A settant'anni dalla Carta Collettiva dell'Episcopato spagnolo: Jerarquía, martirio, memoria colletiva", en Accial, E. y Quaggio, J. (eds.): Un conflitto che non passa. Storia, memoria e rimozioni della guerra civile spagnola, Pistoria, ISRPT, 2012.

Carcel Ortí, V., La gran persecución. España, 1931-1939, Barcelona, Planeta, 2000

Carcel Ortí, V., Caídos, victimas y mártires. La Iglesia y la hecatombe de 1936, Madrid, Espasa, 2008

Casanova, J., La Iglesia de Franco, Barcelona, Crítica, 2005.

Díaz Burillo, V. J., "Integralismo católico posconciliar: un análisis del imaginario político de la Iglesia en democracia", en Romerales, E. y Zazo, E., Religiones en el espacio público, Barcelona, Gedisa, 2016.

Enrique y Tarancón, V., Confesiones, Madrid, PPC, 1996.

Halbwachs, M, Les cadres sociaux de la mémorie. París, Albin Michel, 1995 (1925).

Infiesta, J., "Tarancón, el otro motor del cambio", Cuenta y razón, 96, 1996.

Iribarren, J. (ed.), Documentos colectivos del episcopado español 1870-1974, Madrid, Editorial católica, 1974.

Izquierdo Martín, J., "«Que los muertos entierren a los muertos». Narrativa redentora y subjetividad en la España postfranquista”, Pandora, 12, 2014.

Juliá, S., Historia de las dos Españas, Madrid, Taurus, 2004.

Kritz N. J. (ed.), Transitional Justice: How Emerging Democracies Reckon with Former Regimes. Washington, United States Institute of Peace Press, 3 vols., 1995. 
Martín Descalzo, J. L., Tarancón, el cardenal del cambio, Madrid, Planeta, 1982. Martínez, G. (coord.), CT o la cultura de la transición: Crítica a 35 años de la cultura española. Madrid, Debolsillo, 2012.

Morán, G., El precio de la transición. Madrid, Akal, 2015.

Laboa, J. M., "El cardenal Tarancón, testigo del cambio", Cuenta y razón, 12, 1983.

Puente Ojea, G., Mi embajada ante la Santa Sede. Textos y Documentos, 19851987. Madrid, FOCA, 2002.

Rodrigo, J., Hasta la raíz. Violencia durante la guerra civil y la dictadura franquista. Madrid, Alianza Editorial, 2008.

Teitel, R. G., Transitional Justice, New York, Oxford University Press, 2000.

DOI: http://dx.doi.org/10.15366/bp2018.19.010

Bajo Palabra. II Época. No19. Pgs: 211-228 
